\title{
Abrupt Maturation of a Spike-Synchronizing Mechanism in Neocortex
}

\author{
Michael A. Long, Scott J. Cruikshank, Michael J. Jutras, and Barry W. Connors \\ Department of Neuroscience, Division of Biology and Medicine, Brown University, Providence, Rhode Island 02912
}

Synchronous activity is common in the neocortex, although its significance, mechanisms, and development are poorly understood. Previous work showed that networks of electrically coupled inhibitory interneurons called low-threshold spiking (LTS) cells can fire synchronously when stimulated by metabotropic glutamate receptors. Here we found that the coordinated inhibition emerging from an activated LTS network could induce correlated spiking patterns among neighboring excitatory cells. Synchronous activity among LTS cells was absent at postnatal day 12 (P12) but appeared abruptly over the next few days. The rapid development of the LTS-synchronizing system coincided with the maturation of the inhibitory outputs and intrinsic membrane properties of the neurons. In contrast, the incidence and magnitude of electrical synapses remained constant between P8 and P15. The developmental transformation of LTS interneurons into a synchronous, oscillatory network overlaps with the onset of active somatosensory exploration, suggesting a potential role for this synchronizing system in sensory processing.

Key words: interneuron; inhibition; synchrony; electrical coupling; gap junction; development

\section{Introduction}

Synchronous neuronal activity in the cerebral cortex has been implicated in sensory perception, motor control, attention, and plasticity (Ritz and Sejnowski, 1997; Fetz et al., 2000; Steinmetz et al., 2000; Engel et al., 2001; Levy et al., 2001; Sanes, 2003). In addition, correlated activity has been commonly observed in developing systems and is thought to play an important role in the formation of neural circuits (Katz and Shatz, 1996). Despite the relevance of cortical synchrony, its mechanisms and maturation are poorly understood.

Several findings suggest that inhibitory interneurons play a critical role in the generation of rhythmic, synchronized activity (Cobb et al., 1995; Fuchs et al., 2001; Whittington and Traub, 2003). For example, activation of muscarinic or kainite receptors induces synchronous gamma frequency rhythms that involve fast-spiking (FS) inhibitory interneurons (Traub et al., 2005). The low-threshold spiking (LTS) inhibitory interneurons of the neocortex have several characteristics that might allow them to serve as a general spike-synchronizing mechanism. First, LTS cells form frequent inhibitory connections onto local excitatory cells as well as onto the FS type of inhibitory interneurons (Gibson et al., 1999; Beierlein et al., 2003). Second, LTS neurons are

Received Jan. 27, 2005; revised June 2, 2005; accepted June 23, 2005

This work was supported by National Institutes of Health Grants NS25983 and DA12500. We thank Saundra Patrick for outstanding technical help.

Correspondence should be addressed to Barry W. Connors, Department of Neuroscience, Brown University, Box 1953, Providence, RI 02912.E-mail: bwc@brown.edu.

M. A. Long's present address: Department of Brain and Cognitive Sciences, Massachusetts Institute of Technology, E19-528, 77 Massachusetts Avenue, Cambridge, MA 02139.

M. J. Jutras's present address: Graduate Division of Biological and Biomedical Sciences, Emory University, 1462 Clifton Road, Suite 314, Atlanta, GA 30322.

DOI:10.1523/JNEUROSCI.0375-05.2005

Copyright $\odot 2005$ Society for Neuroscience $\quad$ 0270-6474/05/257309-08\$15.00/0 interconnected by electrical synapses that can strongly synchronize their spiking activity (Gibson et al., 1999, 2005) and thereby allow them to generate synchronous inhibition on a sizeable domain of surrounding cortex (Beierlein et al., 2000; Deans et al., 2001). Third, several neuromodulators induce a robust depolarization of LTS neurons with minimal excitatory effects on other layer 4 neurons in barrel cortex. These include agonists of muscarinic acetylcholine (Xiang et al., 1998; Beierlein et al., 2000), metabotropic glutamate (mGluR) (Beierlein et al., 2000), noradrenergic (Kawaguchi and Shindou, 1998), and serotonergic (S. J. Cruikshank and B. W. Connors, unpublished observations) receptors.

Although several aspects of LTS function have been considered in relatively mature neocortical circuits, the role of these neurons during development is unknown. Here we describe studies of the developing rat somatosensory (barrel) cortex and show that the synchronizing ability of the LTS cell network matures abruptly at the end of the second postnatal week. Thus, concurrent with the onset of active whisking behavior (Welker, 1964), the neocortex acquires a mechanism for rapidly regulating the degree of synchronous spiking among local pyramidal cells.

\section{Materials and Methods}

Thalamocortical slices (350 $\mu \mathrm{m}$ thick) were obtained from Sprague Dawley rats aged postnatal day 8 (P8) to P15 (Agmon and Connors, 1991). Briefly, rats were deeply anesthetized with Nembutal (Abbott Labs, Irving, TX) and intracardially perfused with $10-20 \mathrm{ml}$ of an ice-cold solution containing the following (in mM): $126 \mathrm{NaCl}, 3 \mathrm{KCl}, 1.25 \mathrm{NaH}_{2} \mathrm{PO}_{4}$, $2 \mathrm{MgSO}_{4}, 26 \mathrm{NaHCO}_{3}, 10$ dextrose, and $2 \mathrm{CaCl}_{2}$ (saturated with $95 \%$ $\mathrm{O}_{2} / 5 \% \mathrm{CO}_{2}$ ). After perfusion, the brain was rapidly removed, and slices were made with a vibratome while slowly advancing the blade manually (Campden Instruments, Lafayette, IN). The slices were incubated for 45 min at $32^{\circ} \mathrm{C}$ and then kept at room temperature until they were transferred to a $32^{\circ} \mathrm{C}$ submersion-style recording chamber. 
Paired intracellular recordings of neurons within rat primary somatosensory (barrel) neocortex were the main method used in this investigation. Whole-cell micropipettes were filled with the following (in $\mathrm{mm}$ ): 130 potassium gluconate, $4 \mathrm{KCl}, 2 \mathrm{NaCl}, 0-10$ sucrose, 10 HEPES, 0.2 EGTA, 4 ATP-Mg. 0.3 GTP-Tris, and 7 phosphocreatine-Tris pH 7.2-7.3 $(280 \mathrm{mOsm})$. All recordings were made in current-clamp mode (Axon Instruments, Union City, CA). Infrared differential interference contrast visualization was performed using a Zeiss (Oberkochen, Germany) Axioskop and a CCD camera (Hamamatsu, Bridgewater, NJ). Before targeting an area for recording, the slice was viewed with a lowmagnification objective. This allowed for us to clearly visualize characteristics of layer 4 (i.e., the presence of layer 4 barrels, relatively high contrast with respect to surrounding tissue, and characteristic distance from layer 1). With the high-power immersion lens, the border between layers 5 and 4 was easily visualized. The border between 3 and 4 was less clear, so we restricted our recordings to the middle and deep portions of layer 4. In addition, all of the biocytin-filled LTS cells were confirmed to be within layer 4 .

The mGluR (groups I and II) agonist $(1 S, 3 R)$-1-aminocyclopentane1,3-dicarboxylic acid (ACPD) (100 $\mu \mathrm{M})$ was obtained from Tocris Cookson (Ballwin, MO). Some experiments were performed with $20 \mu \mathrm{M}$ DNQX (Sigma, St. Louis, MO) and $50 \mu \mathrm{M}$ APV (Sigma) present to block AMPA- and NMDA-type glutamate receptors, respectively. Data were analyzed with auto- and cross-correlograms and power spectra using Labview software (National Instruments, Austin, TX). Subthreshold membrane potentials were bandpass filtered $(1.5-70 \mathrm{~Hz})$ for analysis. The correlograms were first averaged and then normalized by the product of the SD of the amplitude of the signal in each recording, as described previously (Beierlein et al., 2000). The correlation coefficient for each pair was the average cross-correlation of five epochs of $2 \mathrm{~s}$ each, for each pair, after administration of ACPD. Action potential cross-correlations were calculated in $10 \mathrm{~s}$ epochs ( $300 \mathrm{~ms}$ analysis window; bin size, $20 \mathrm{~ms}$ ). To compare across cell pairs, the correlograms were normalized. First, spike numbers in each bin were divided by the total number of spikes in the reference cell, and then baseline correlations were zeroed out by subtracting the across-bin average from each individual bin.

To test for the presence of inhibitory connections between LTS and regular-spiking (RS) cells, short (5 ms) current pulses (200-400 pA) were applied to evoke an action potential in LTS cells $(0.1 \mathrm{~Hz})$. The amplitude of the IPSP was measured from the averaged responses to $10-50$ unitary LTS action potentials at a holding potential of -50 to -53 $\mathrm{mV}$. To estimate the IPSP reversal potential in LTS-to-RS connected pairs, at least $10 \mathrm{RS}$ responses were averaged at $-50,-60,-70,-80$, and $-90 \mathrm{mV}$. The amplitude of the IPSP was plotted against the holding potential to estimate the reversal potential for each neuron.

For the anatomical reconstructions, cells were filled through the whole-cell pipettes for at least $20 \mathrm{~min}$ with biocytin $(4 \mathrm{mg} / \mathrm{ml})$. Slices were then incubated in $4 \%$ paraformaldehyde solution for at least $24 \mathrm{~h}$, before being transferred to a cryoprotectant solution (30\% sucrose/4\% paraformaldehyde). Tissue was resectioned into $80-\mu \mathrm{m}$-thick slices using a microtome, and biocytin labeling was revealed using 3,3'diaminobenzidine (Sigma). Neuronal morphology was reconstructed using a camera lucida attached to a light microscope with a $40 \times$ objective. We applied three different analyses to these reconstructions to quantify and compare the structural organization of dendritic and axonal arborizations between age groups. Initially, we counted the number of intersections that occurred across a series of concentric circles $(10 \mu \mathrm{m}$ spacing) radiating from the somata (Sholl, 1953). To examine the vertical extent of axonal arborization, we used a grid of parallel lines spaced $20 \mu \mathrm{m}$ apart and aligned parallel to the orientation of the pial surface (adapted from Xiang et al., 1998). Intersections between these lines and either axonal or dendritic branches were counted. Measurements were gathered into groups by averaging adjacent measurements into bins of $100 \mu \mathrm{m}$.

All data are presented as mean \pm SD unless otherwise noted. Paired comparisons between groups were tested with a two-tailed Student's $t$ test unless otherwise noted.
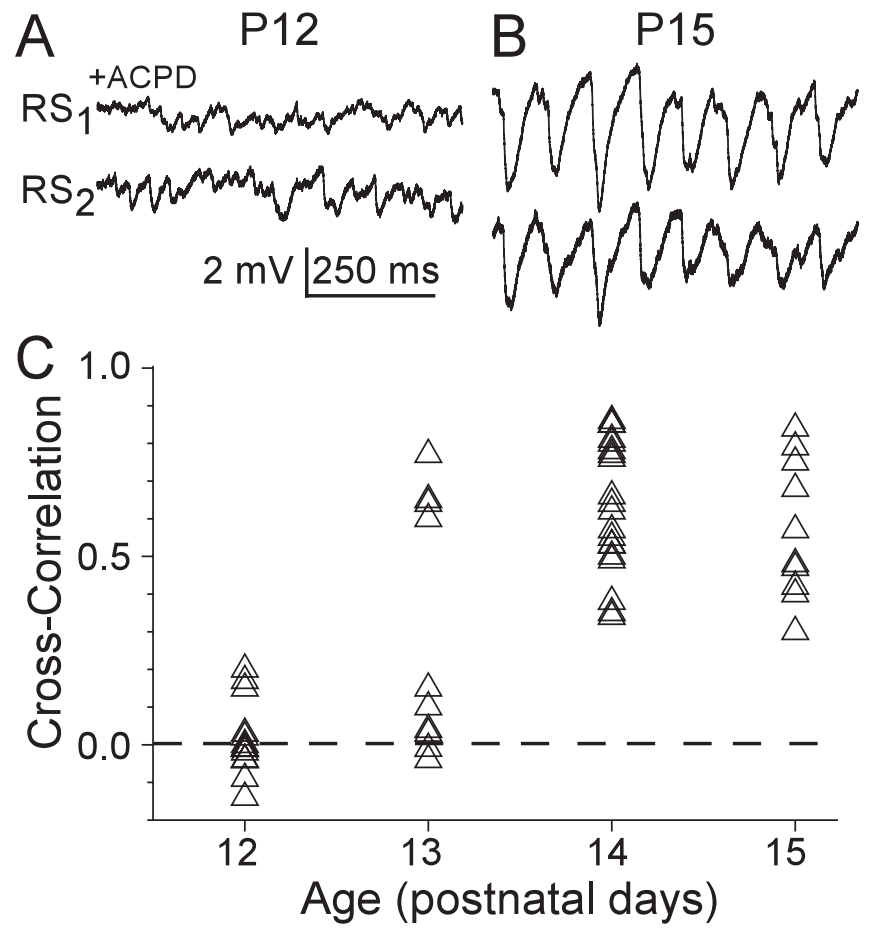

Figure 1. Rapid onset of ACPD-induced correlated inhibition. A, At P12, ACPD (100 $\mu \mathrm{M})$ leads to weak and uncorrelated inhibition in RS cells. $\boldsymbol{B}, \mathrm{At} P 15$, inhibition becomes strongly correlated across RS pairs. C, Population data demonstrates rapid developmental onset of correlated inhibition between $P 12$ and $P 15$. Each triangle represents the correlation coefficient of an RS-RS pair at time $0 . P 12, n=15$ pairs, 3 animals; $P 13, n=10$ pairs, 3 animals; $P 14, n=$ 20 pairs, 5 animals; $P 15, n=10$ pairs, 2 animals.

\section{Results}

Whole-cell recordings were made in layer 4 of primary somatosensory cortex from juvenile rats. All neurons were classified according to their intrinsic membrane properties and synaptic connections (Gibson et al., 1999; Beierlein et al., 2003). Neurons clearly identified as excitatory RS cells and inhibitory LTS cells were included in these analyses.

Once stable paired-cell recordings were obtained, the mGluR agonist ACPD $(100 \mu \mathrm{M})$ was applied through the bathing solution. At P12, ACPD induced IPSPs that were small, irregular, and poorly synchronized across RS cell pairs (Fig. $1 A$ ). In P15 rats, however, ACPD elicited a 3-5 min episode of vigorous, rhythmic IPSPs in RS cells. IPSPs were tightly synchronized across pairs of neighboring neurons (Fig. $1 \mathrm{~B}$ ), as reported previously (Beierlein et al., 2000; Deans et al., 2001). Within a sample of 55 RS-RS cell pairs from P12 to P15, the synchrony of mGluR-induced IPSPs was strongly correlated with age (Fig. $1 C)(r=0.74 ; p<0.0001)$. The maturation of this synchronous inhibitory mechanism was abrupt; it was entirely absent at P12 and fully expressed by P14. At P13, inhibitory synchrony was bimodally distributed, and cells showed either uncorrelated or strongly correlated inhibition (Fig. $1 C$ ). The modal frequency of synchronous inhibitory events in ACPD ranged from $\sim 4$ to $12 \mathrm{~Hz}$.

We tested the ability of mGluR-activated IPSPs to synchronize the spiking patterns of excitatory RS cells (which are the targets of inhibitory synapses from LTS cells). RS cell pairs were stimulated to fire with long steps of depolarizing current, and their synchrony was compared in the presence versus absence of ACPD. In P15 cortices, ACPD produced highly correlated action potentials in neighboring RS pairs, presumably mediated by the synchronous IPSPs that were observed between spikes (Fig. $2 B, D, F$ ). 

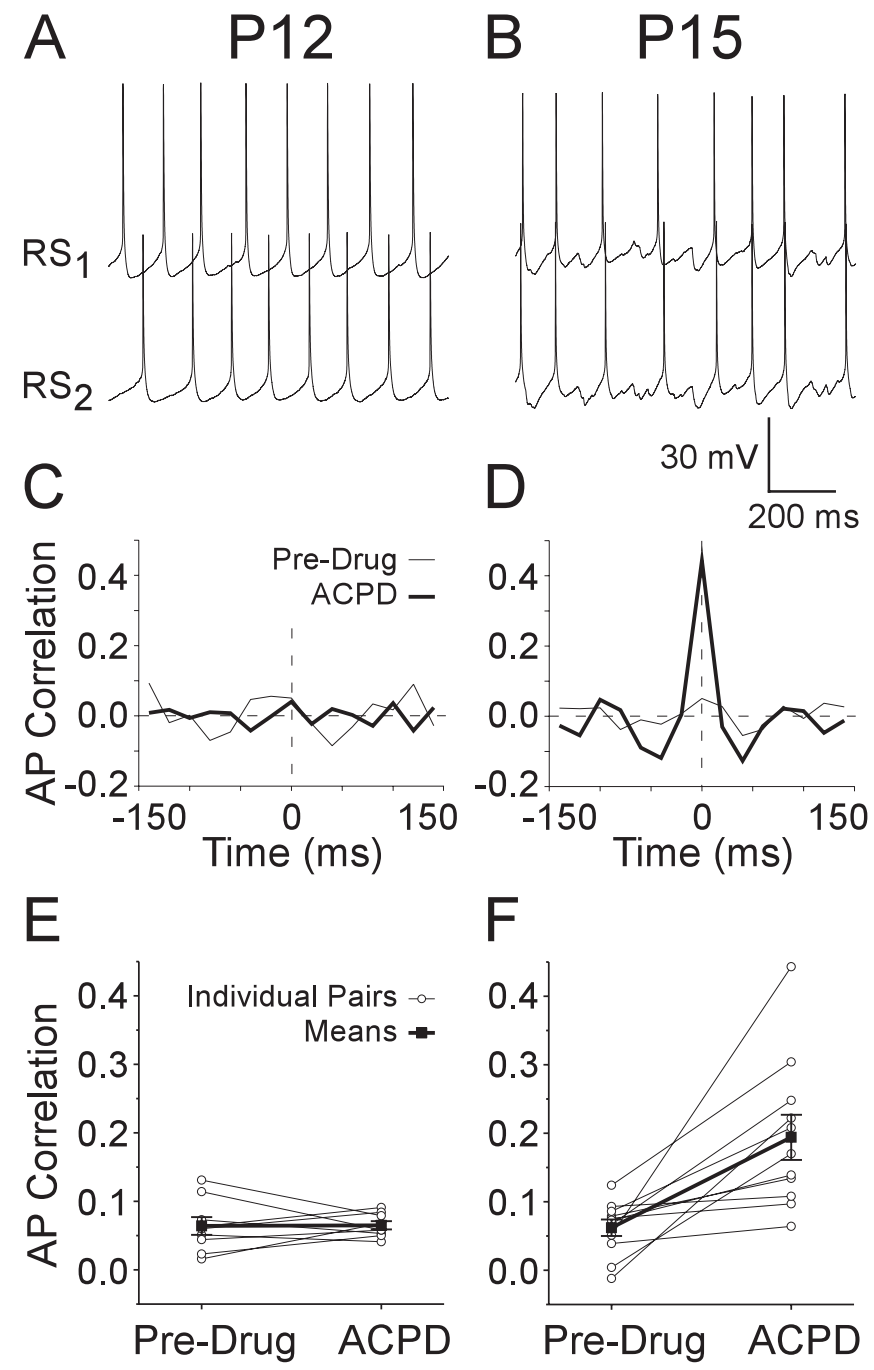

Figure 2. Correlated inhibition leads to spike synchrony in RS cells. Left panels show P12 data $(\boldsymbol{A}, \boldsymbol{C}, \boldsymbol{D})$, and right panels show $P 15(\boldsymbol{B}, \boldsymbol{D}, \boldsymbol{F}) . \boldsymbol{A}$, Example of spiking activity in two closely spaced RS cells from a P12 animal during bath application of $100 \mu \mathrm{m}$ ACPD. Note the lack of spike alignment between cells. $\boldsymbol{B}$, Action potentials in a pair of P15 RS cells. There is clear alignment of both spikes and IPSPs between cells. C, D, Action potential cross-correlograms for the pairs shown in $\boldsymbol{A}$ and $\boldsymbol{B}$ above (bin width, $20 \mathrm{~ms}$ ). Multiple 10 s epochs ( $\geq 6$ ) were acquired for each cell pair in both the predrug and ACPD conditions. The three epochs with highest central bin values (i.e., strongest correlations) were averaged for each condition to produce the plots shown here. Note the relatively flat correlograms for the P12 pair, indicating poor spike correlation (C). For the P15 pair, the predrug correlogram is likewise flat, but there is a large peak at time 0 during $A C P D$, indicating a high degree of synchrony $(\boldsymbol{D}) . \boldsymbol{E}, \boldsymbol{F}$, Group measures for spike synchrony in RS pairs (P12,n=9; P15, $n=11)$. For each cell pair, cross-correlations were calculated as in $\mathbf{C}$ and $\boldsymbol{D}$, and then the central $20 \mathrm{~ms}$ bin was extracted as a measure of action potential correlation ( $y$-axis) and plotted as a function of condition (predrug and ACPD). Individual pair and mean \pm SEM values are both shown. ACPD had no effect on action potential (AP) correlation in the P12 pairs $(\boldsymbol{E})$ but produced a significant increase in the $\mathrm{P} 15$ pairs $(p<0.005$, paired $t$ test). The spike correlation values during ACPD were significantly higher for $P 15$ than $\mathrm{P} 12(p<0.005$, unpaired $t$ test), whereas the predrug values were not different for the two ages ( $p=0.91$, unpaired $t$ test). The latter were slightly above zero (P12 mean, $0.064 \pm .013$; P15 mean, $0.062 \pm 0.012$ ) because the three epochs with highest central bins were used for analysis.

Note that ionotropic glutamate receptors were blocked (50 $\mu \mathrm{M}$ APV and $20 \mu \mathrm{M}$ DNQX), preventing any effects of fast excitatory transmission between the RS cells. The central bin of the spike cross-correlograms, which reflects the degree of spike synchrony, increased significantly during ACPD for the P15 pairs (Fig. $2 D, F)(p<0.005$, paired $t$ test, ACPD vs predrug). In contrast,

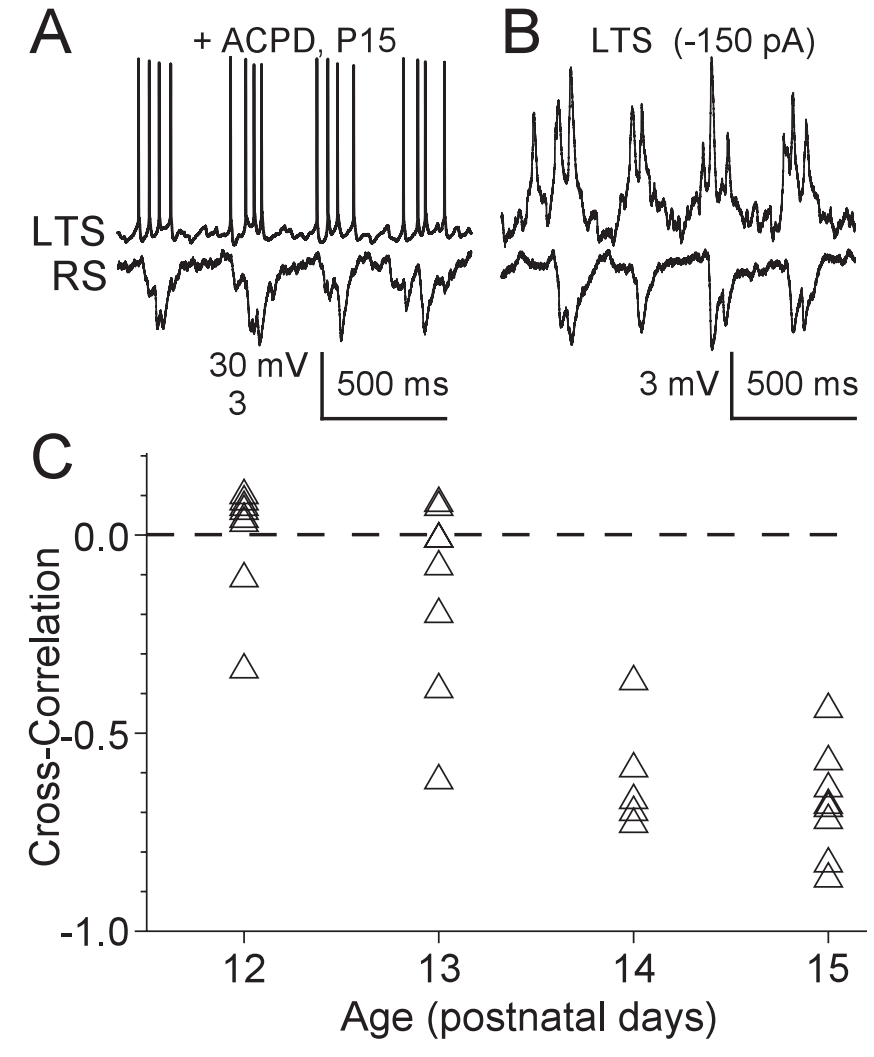

Figure 3. Synchronous inhibition in ACPD is provided by the LTS network. A, ACPD causes strong depolarization of LTS cells, including episodes of regular bursting behavior that are correlated with IPSPs in output cells. $\boldsymbol{B}$, Hyperpolarizing holding current reveals subthreshold depolarizations in LTS cells that are anticorrelated with inhibitory output. C, ACPD-induced LTS-RS antisynchrony is correlated with age. Each triangle represents the correlation coefficient of an LTS-RS pair at time 0 . Hyperpolarizing current was injected to keep LTS cells below threshold. $P 12, n=8$ pairs, 4 animals; $P 13, n=9$ pairs, 4 animals; $P 14, n=8$ pairs, 5 animals; $\mathrm{P} 15, n=11$ pairs, 6 animals.

ACPD had no effect on spike correlations in P12 cell pairs (Fig. $2 A, C, E)(p=0.94$, paired $t$ test $)$.

What accounts for the abrupt maturation of this spikesynchronizing mechanism? Previous studies demonstrated that a network of electrically coupled LTS interneurons can drive synchronous mGluR-induced inhibition (Beierlein et al., 2000; Deans et al., 2001). When LTS cells from P15 were excited by ACPD, their spikes were tightly correlated with rhythmic IPSPs in neighboring RS cells (Fig. 3A). Hyperpolarizing LTS cells with injected current revealed that rhythmic fluctuations of membrane potential underlie mGluR-induced spiking (Fig. 3B). At P15, subthreshold voltage fluctuations of LTS cells were strongly anticorrelated with rhythmic IPSPs recorded from neighboring RS cells (mean peak correlation, $-0.68 \pm 0.14$ ). However, at P12, the activity of LTS and RS cell pairs was entirely uncorrelated in the presence of ACPD (mean peak correlation, $0.00 \pm 0.15$ ), and there was a general paucity of subthreshold activity in both cell populations. The relationship between induced LTS cell activity and RS cell inhibition developed between P12 and P15 (Fig. 3C) $(r=-0.84 ; p<0.0001)$, with the same developmental schedule seen for the synchrony of mGluR-induced inhibition (Fig. 1C). This similarity reinforces the notion that the maturation of the spike-synchronizing mechanism is attributable to developmental changes in the LTS network or its inhibitory synapses.

As one measure of the maturation rate of LTS interneurons, we examined their dendrites $(n=12)$ and axons $(n=6)$ between P12 


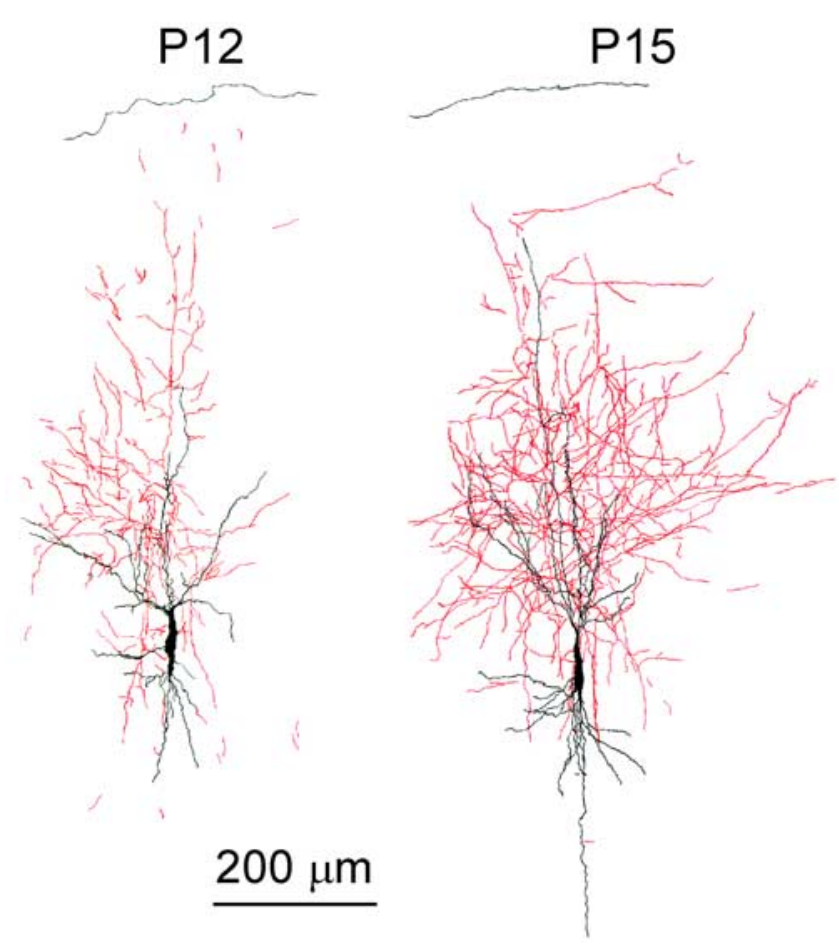

Figure 4. Dendritic and axonal arbors of LTS cells become more elaborate between P12 and $P 15$. Reconstructions of biocytin-filled LTS cells at P12. Arborization is markedly increased at P12 and P15, especially in the vertical domain (red, axons; black, dendrites).

and P15. Physiologically identified LTS cells from layer 4 were filled with biocytin and reconstructed using camera lucida (Fig. 4). In general, the dendrites of LTS cells had a vertical bias to their orientation (Amitai et al., 2002), and their axons extending upward from the somata were the most dense. Both dendrites (Fig. 5A) and axons (Fig. $5 B$ ) of LTS cells also showed an age-dependent increase in the total number of crossings of concentric circles originating at the soma (Sholl, 1953). Several bins achieved differences that were statistically significant $(p<0.05)$ in both the axonal $(225$ and $275 \mu \mathrm{m})$ and dendritic (175-275 $\mu \mathrm{m})$ analyses. The extent of arborization was estimated by the number of times that axons or dendrites crossed evenly spaced lines that were parallel to the pia (Xiang et al., 1998). The total number of crossings of both dendrites (Fig. 5C) and axons (Fig. 5D) increased between P12 and P15 (dendritic crossings, $97 \pm 43$ to $122 \pm 21$; axonal crossings, $330 \pm 152$ to $449 \pm 59$ ), implying an increase in the total length of neuronal processes. Most of this growth occurred from 300 and $600 \mu \mathrm{m}$ below the pia, corresponding to lower layer $2 / 3$ and the border region with layer 4 , including a doubling of the number of axonal crossings from $154 \pm$ 140 to $301 \pm 79.6$.

The synchronization of mGluR-induced IPSPs depends strongly on the presence of electrical synapses between LTS cells (Beierlein et al., 2000; Deans et al., 2001). Because there is evidence that electrical coupling between neurons is strongly regulated during cortical development (Connors et al., 1983; Lo Turco and Kriegstein, 1991; Peinado et al., 1993; Galarreta and Hestrin, 2002; Meyer et al., 2002), it is possible that maturation of electrical coupling underlies the development of LTS-mediated synchrony. To test for changes in electrical synapses, we recorded from LTS cell pairs from ages P8-P15. Figure $6 A$ shows examples of electrically coupled LTS pairs from P12 and P15. Across a sample of 21 pairs of closely spaced (intersomatic distance $<50$ $\mu \mathrm{m})$ LTS cells, neither the strength nor the incidence of electrical coupling varied with age (Fig. $6 B$ ).
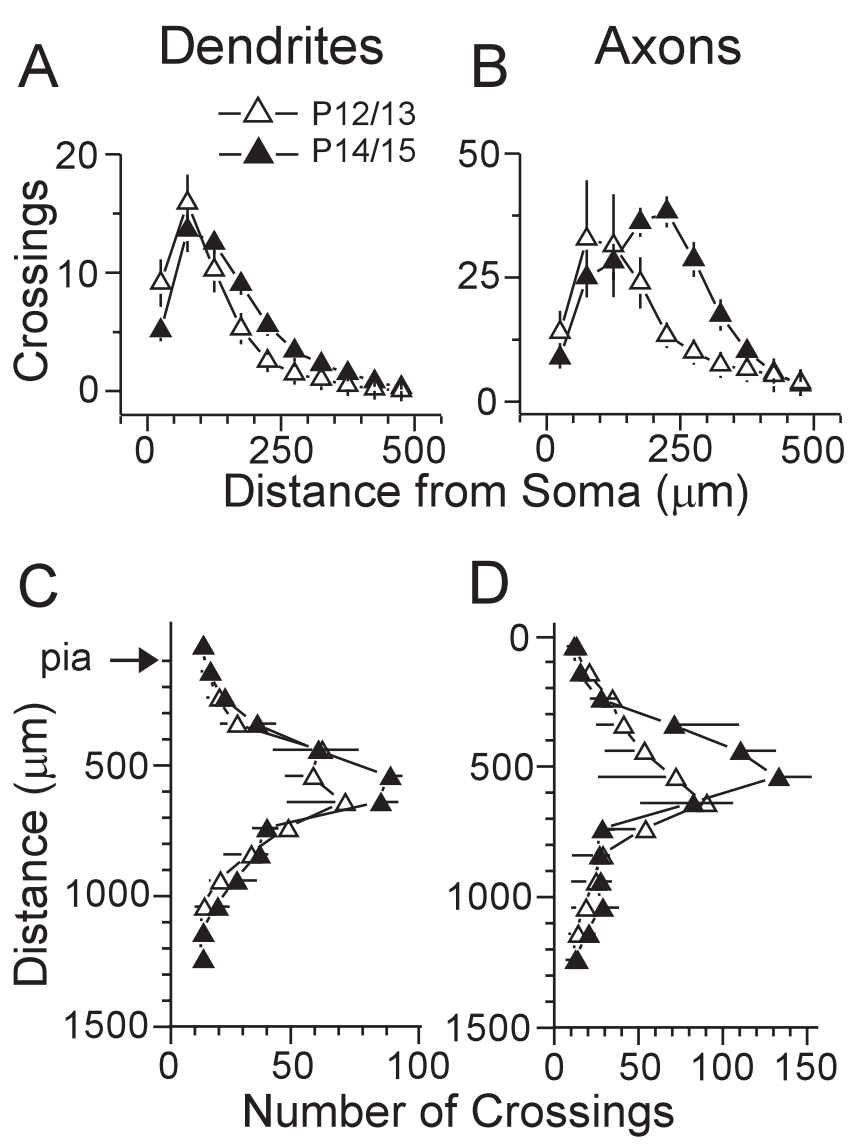

Figure 5. Quantification of developmental changes in LTS morphology. Axonal (P12, $n=3$; $\mathrm{P} 14 / \mathrm{P} 15, n=3)$ and dendritic (P12, $n=6 ; \mathrm{P} 14 / \mathrm{P} 15, n=6)$ arborization is quantified using a Sholl analysis $(\boldsymbol{A}, \boldsymbol{B})$. An increase in vertical spread of dendrites $(\boldsymbol{C})(\mathrm{P} 12, n=6 ; \mathrm{P} 14 / \mathrm{P} 15, n=$ 5) and axons (P12, $n=3 ; P 14 / P 15, n=3)(D)$ into upper cortical layers between P12 and P15 (bin width, $100 \mu \mathrm{m})$. Data are plotted as mean $\pm \mathrm{SE}$.

A sudden increase in the strength or number of inhibitory synapses originating from LTS cells could account for the abrupt onset of synchronous inhibition. We tested inhibition directly by recording from 57 pairs of LTS-RS cells from P12 to P15. There was a weak relationship between age and the probability of LTSto-RS inhibitory connections ( 0.43 at P12/P13; 0.52 at P14/P15). The strength of these inhibitory connections, defined as the average amplitude of unitary LTS-to-RS IPSPs (Fig. 7A), increased from P12 $(-0.52 \pm 0.26 \mathrm{mV})$ to $\mathrm{P} 15(-0.79 \pm 0.37 \mathrm{mV})$, as reflected in the cumulative probability histogram (Fig. $7 B$ ). There was a significant increase in inhibitory synaptic strength across all sampled pairs from P12 to P15 ( $r=-0.40 ; p<0.05)$.

Nonsynaptic factors did not have a significant effect on the change in unitary IPSP size observed between P12 and P15. The input resistance of RS cells decreased from P12 $(280 \pm 68 \mathrm{M} \Omega$; $n=9)$ to P15 (235 $\pm 79 \mathrm{M} \Omega ; n=9)$, which by itself would have slightly reduced the amplitude of IPSPs as cells matured. The IPSP reversal potential was indistinguishable between P12 $(-81.3 \pm 1.0 \mathrm{mV} ; n=5)$ and $\mathrm{P} 15(-82.1 \pm 2.0 \mathrm{mV} ; n=5)$. In addition, RS neurons were given depolarizing current to bring their membrane potentials to between -50 and $-53 \mathrm{mV}$ while testing for inhibitory connectivity. As a result, changes in unitary IPSP size in LTS-RS pairs probably reflected an increase in the mean inhibitory synaptic conductance.

Maturation of the intrinsic properties of LTS cells could contribute to the onset of the spike-synchronizing mechanism. Input resistance $(r=-0.59 ; p<0.0001)$ and membrane time constant 


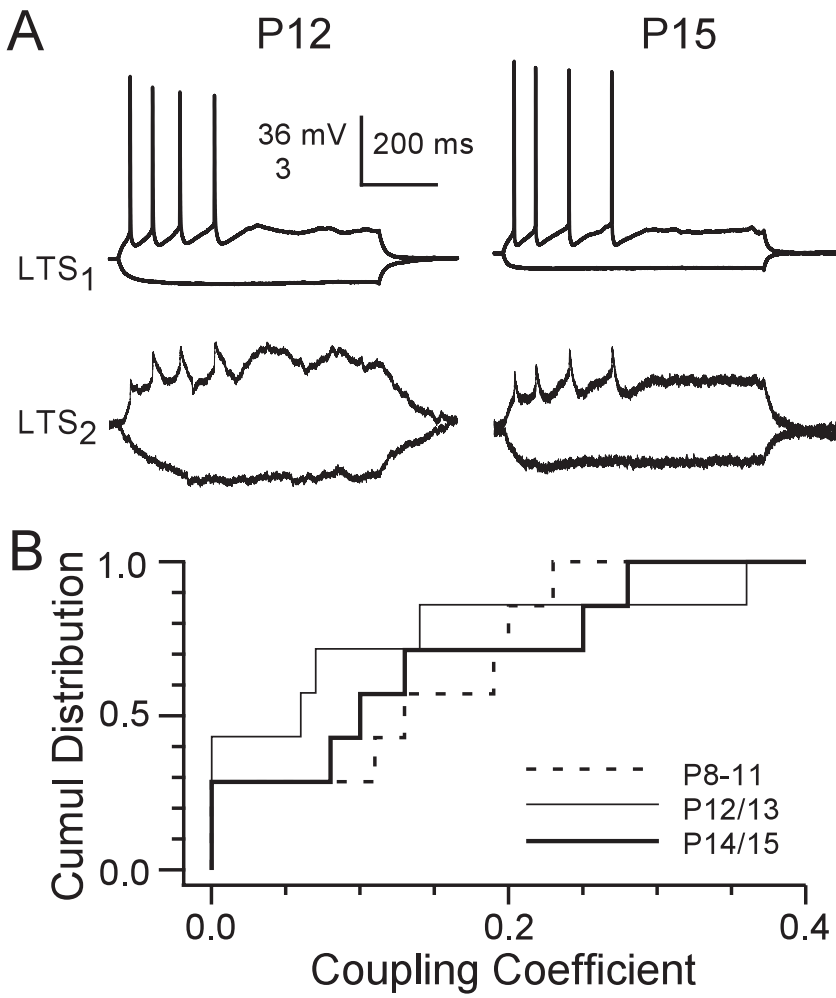

Figure 6. Strength of LTS-LTS electrical coupling is not developmentally regulated. $\boldsymbol{A}$, Responses of LTS-LTS pairs to depolarizing and hyperpolarizing current at P12 and P15 show comparable electrical coupling. $\boldsymbol{B}$, The incidence and strength of electrical coupling is not developmentally regulated between $\mathrm{P} 8$ and $\mathrm{P} 15$, as shown by an overlapping cumulative frequency histogram. P8 -P11, $n=7$ pairs, 4 animals; P12/P13, $n=7$ pairs, 6 animals; P14/P15, $n=7$ pairs, 6 animals.

$(r=-0.65 ; p<0.0001)$ dropped, and spike-frequency adaptation rates increased $(r=-0.60 ; p<0.0001)$ between P12 and P15 (supplemental Fig. 1, available at www.jneurosci.org as supplemental material). Developing LTS cells also became more sensitive to mGluR activation. In response to ACPD, every LTS cell recorded in the absence of injected current was strongly depolarized and generated spikes ( $n=47$; ages P12-15), including all 14 cells from age P12. However, the frequency of ACPD-induced spiking was positively correlated with age $[r=0.62 ; p<0.001$; mean spike rate was $10.4 \pm 6.8 \mathrm{~Hz}$ at $\mathrm{P} 12(n=8)$ and $22.3 \pm 6.8$ $\mathrm{Hz}$ at P15 $(n=10)]$. Furthermore, the coefficient of variation of spike intervals in ACPD-treated LTS cells increased from P12 $(0.29 \pm 0.13 ; n=8)$ to $\mathrm{P} 15(0.52 \pm 0.23 ; n=10)$. These results could be attributable to age-dependent changes in the expression of mGluRs or their downstream signaling pathways and membrane channel effectors. The subthreshold characteristics of mGluR-induced activity also changed (Fig. $8 \mathrm{~A}$ ). Both the magnitude (Fig. $8 B)(r=0.62 ; p<0.0001)$ and the dominant frequency (Fig. $8 C)(r=0.49 ; p<0.0002)$ of ACPD-induced rhythms increased dramatically from ages P12 to P15. This implies that the maturation of LTS cell physiology is a major contributor to the abrupt appearance of the spike-synchronizing mechanism.

One of the most remarkable features of the LTS cell population is its ability to evoke synchronized inhibition over a large volume of cortical circuitry (Beierlein et al., 2000). This presumably arises from the dense and spatially extended nature of electrical coupling within the LTS cell network (Deans et al., 2001; Amitai et al., 2002). Here we found that pairs of older LTS cells (P14-P15) could generate strongly synchronized subthreshold
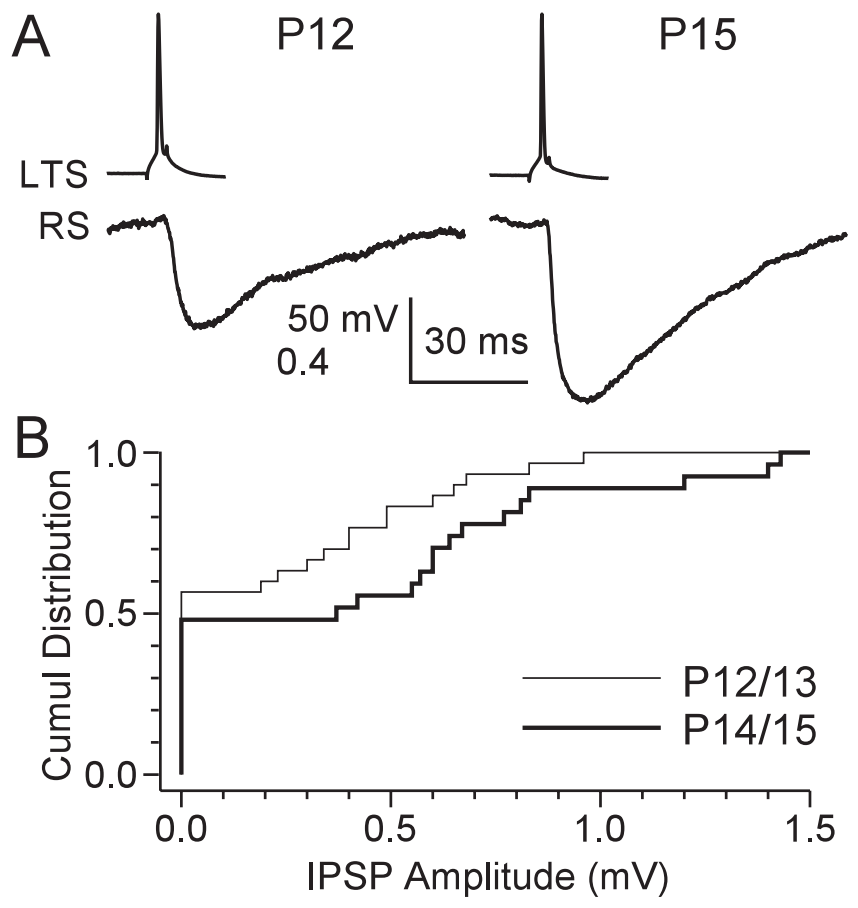

Figure 7. Strength of LTS-to-RS inhibition is developmentally regulated. $\boldsymbol{A}$, In a synaptically connected LTS-RS pair, RS postsynaptic responses to evoked LTS spike showed an increase in LTS-to-RS connections from P12 to P15. Each IPSP represents the average of 50 responses. $\boldsymbol{B}$, Cumulative frequency histogram reflected an population increase in LTS-to-RS synaptic strength from P12/P13 to P14/P15.P12, $n=21$ pairs, 9 animals; P13, $n=9$ pairs, 4 animals; $P 14, n=8$ pairs, 5 animals; $P 15, n=19$ pairs, 8 animals.

fluctuations even when there was no measurable electrical coupling between them, as in the example shown in Figure 9A. This widely spaced $(250 \mu \mathrm{m})$ pair, which had a negligible coupling coefficient, was strongly synchronized when activated by ACPD. Fast chemical synaptic transmission was blocked in these experiments, implying that synchrony likely resulted from interactions via electrical synapses in intervening LTS cells. Similar recordings made from variably spaced LTS-LTS cell pairs showed that electrical coupling was common among the closest cell pairs at all ages tested (Fig. 9B, filled symbols). The mGluR-induced activity of the electrically coupled pairs was highly correlated at P14-P15 (correlation coefficient of $0.82 \pm 0.13$; triangles) and less strongly correlated at P12 $(0.51 \pm 0.13)$. The more distantly spaced cells were not electrically coupled (Fig. 9B, open symbols), and mGluR-induced activity was uncorrelated in the uncoupled LTS cell pairs at P12 (0.03 \pm 0.03$)$. At P14-P15, however, a substantial degree of synchrony remained, even between widely spaced, electrically uncoupled pairs $(0.53 \pm 0.23$; $p<0.005)$.

\section{Discussion}

Our results show that a spike-synchronizing mechanism develops rapidly in the adolescent rat neocortex between P12 and P15. At P12, mGluR activation resulted in weak and uncorrelated inhibition within RS neurons. At P15, the same treatment invariably led to episodes of rhythmic, synchronized IPSPs that were capable of synchronizing spikes among RS cells. These mGluRactivated rhythms are mediated by an electrically coupled system of LTS inhibitory interneurons (Gibson et al., 1999; Beierlein et al., 2000). The precise mechanisms underlying the rapid maturation of the spike-synchronizing system remain unclear, but several developmental modifications of the LTS network and its synaptic connections probably contribute. 


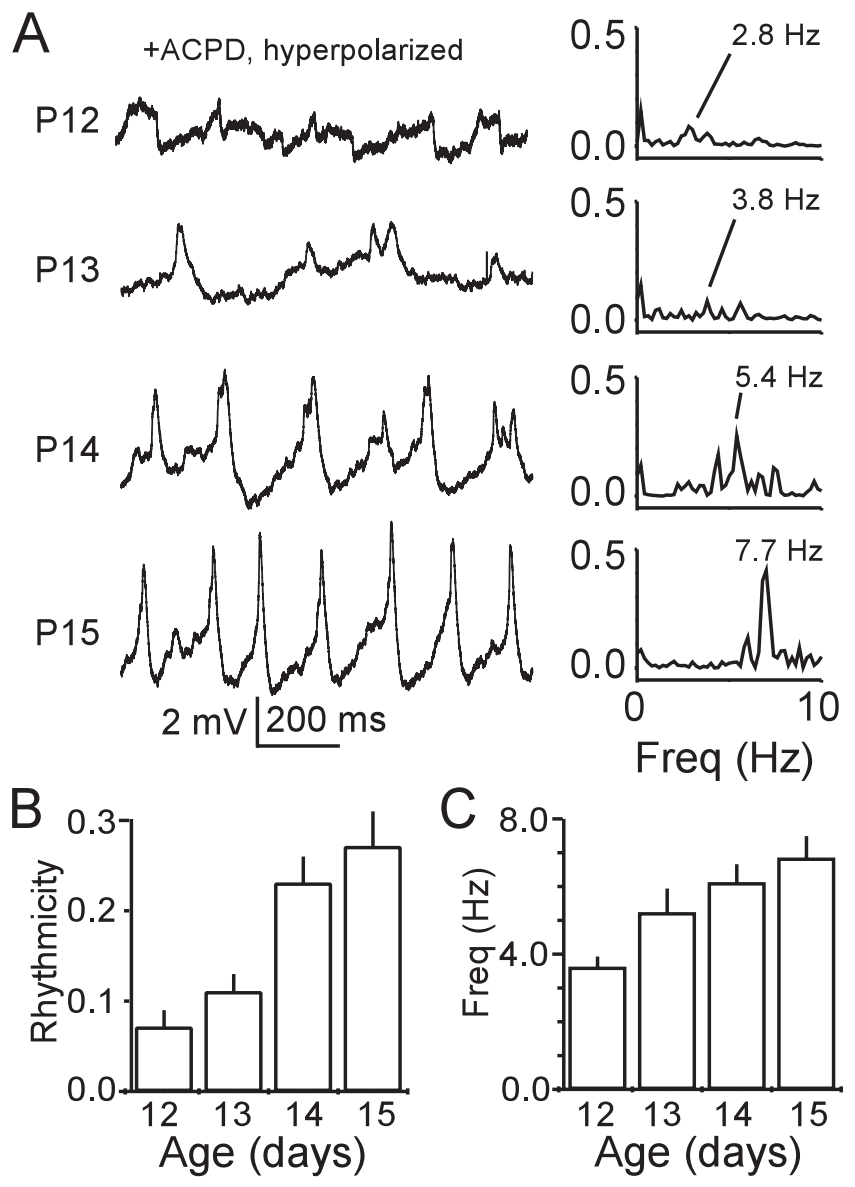

Figure 8. Maturation of ACPD-induced LTS rhythms. A, Between P12 and P15, ACPD-evoked rhythms in LTS cells become more regular and robust. The peak frequency of these rhythms (displayed by accompanying power spectra) increases during this time. Example traces were chosen because the frequency and rhythmicity matched mean values for each age. Power spectra were performed on $5 \mathrm{~s}$ epochs, including the $1 \mathrm{~s}$ examples displayed. B, ACPD-induced rhythmicity [derived from auto-correlogram side-peak (Long et al., 2004)] increases between P12 and P15. C, The dominant frequency of ACPD-induced rhythms increases between P12 and P15.P12, $n=16$ cells, 4 animals; P13, $n=14$ cells, 4 animals; P14, $n=15$ cells, 6 animals; P15, $n=13$ cells, 4 animals.

\section{Mechanisms for the rapid development of LTS-mediated synchrony}

During the second and third postnatal weeks, the rat neocortex undergoes massive changes of neuronal and synaptic properties (Miller, 1988). Most of these occur much more gradually than the rapid onset of the LTS-mediated rhythms. For example, the intrinsic physiology and morphology of pyramidal cells develop gradually over the first 3 postnatal weeks in rats (McCormick and Prince, 1987; Franceschetti et al., 1998). The cellular properties relevant to LTS-mediated activity have not been studied previously during development.

\section{Development of mGluR agonist sensitivity}

The emergence of the spike-synchronizing mechanism may be attributable, in part, to an increase in the sensitivity of LTS cells to ACPD. A previous study demonstrated that the $\mathrm{mGluR} 1 \alpha$ receptor subtype on LTS cells mediates rhythmic, synchronized responses to ACPD (Beierlein et al., 2000). Levels of mGluR1 $\alpha$ immunoreactivity increase in a subpopulation of neocortical interneurons between P10 and P30 (Lopez-Bendito et al., 2002). It is conceivable that LTS cells lack either mGluR $1 \alpha$ or its effector system at P12, and that these are strongly upregulated by P15.
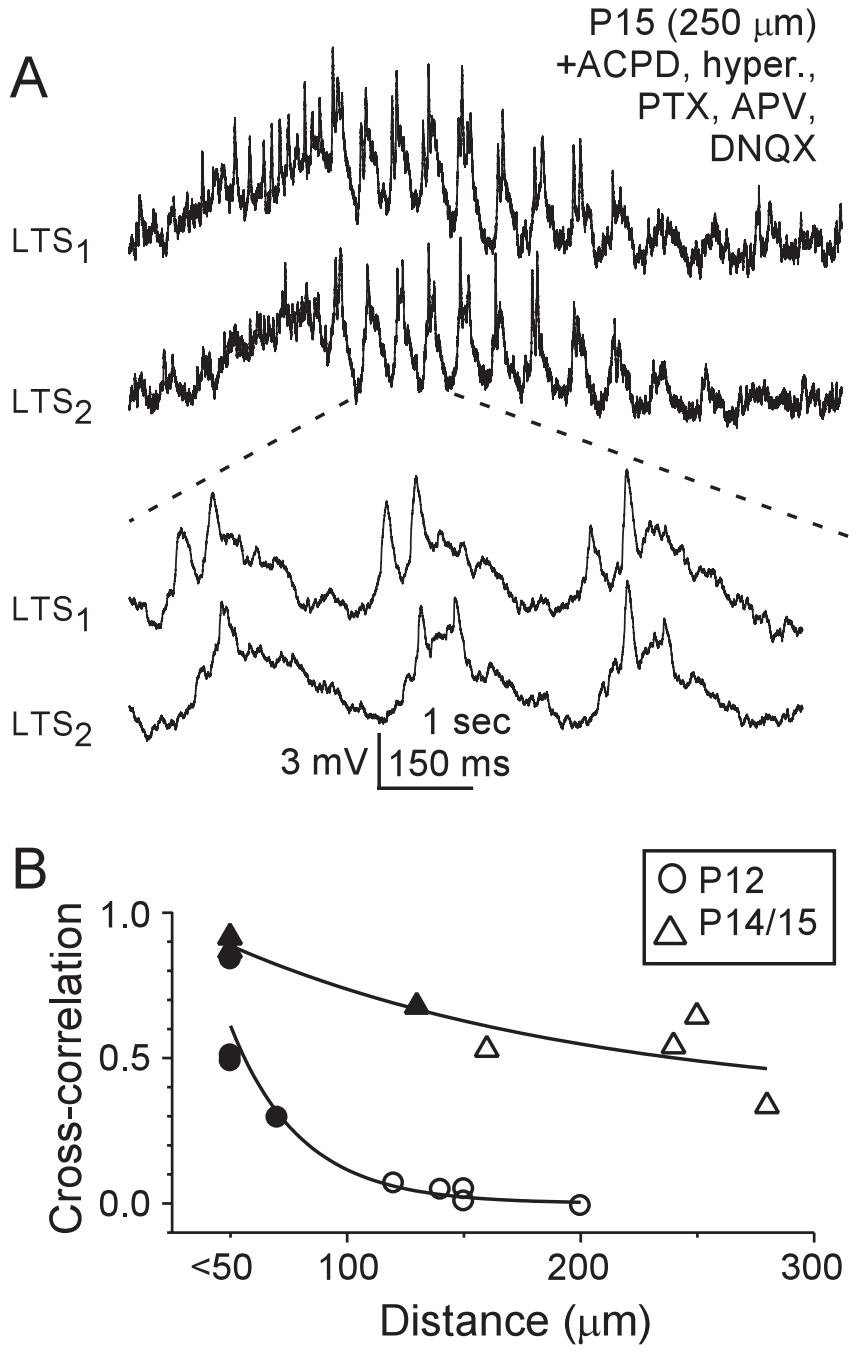

Figure 9. LTS rhythmicity allows for long-distance synchrony. A, An LTS pair (intersomatic distance, $250 \mu \mathrm{m}$ ) in the presence of ACPD generates synchronous rhythms despite not being directly electrically coupled. $\boldsymbol{B}$, The spread of synchrony at $\mathrm{P} 15$ is far greater than at $\mathrm{P} 12$. The correlation coefficient of LTS-LTS pairs at varying intersomatic distances is plotted for P12 (circles; $n=9$ ) and P14/P15 (squares; $n=7$ ) (filled symbols, directly coupled; open symbols, not directly coupled). P12, $n=9$ pairs, 5 animals; P14/15, $n=7$ pairs, 4 animals.

This seems unlikely, however, because we found that ACPD strongly depolarized LTS cells at P12 and triggered them to spike in all cases. The effects of activating mGluRs, and perhaps the variety of ion channels they modulate, may change more strongly from P12 to P15. In hippocampal pyramidal cells, group I mGluR receptors can both activate inward currents and suppress potassium conductances (Heuss et al., 1999; Gee et al., 2003; Young et al., 2004). Additional work will be needed to determine the specific ion channels involved in generating neuromodulatorevoked rhythms in neocortical LTS cells.

Electrical coupling in the LTS cell network

LTS cells form one of several electrically coupled networks of inhibitory cells in neocortex (Galarreta and Hestrin, 1999; Gibson et al., 1999, 2005; Blatow et al., 2003; Chu et al., 2003; Connors and Long, 2004; Galarreta et al., 2004). Although they make profuse GABAergic connections with both FS and RS cells, LTS cells rarely inhibit one another, so electrical synapses are their primary means of interaction (Gibson et al., 1999). Data from the connexin36 knock-out mouse, which is nearly devoid of electrical synapses between LTS cells, sug- 
gest that electrical synapses are crucial for the generation of robust and rhythmic ACPD-induced inhibition (Deans et al., 2001). However, our data demonstrated that neither the incidence nor the strength of electrical coupling between LTS-LTS pairs changed between P8 and P15. One potential problem in interpreting these results is that they were on closely apposed $(<50 \mu \mathrm{m})$ pairs. In a sample of LTS neurons aged P14-P21, pairs with intersomatic distances of $200 \mu \mathrm{m}$ or more were never coupled (Amitai et al., 2002). An age-dependent increase in the probability and strength of more distant (50-200 $\mu \mathrm{m})$ LTS pairs could contribute to the long-range synchrony that emerges between P12 and P15.

Signals transferred across electrical synapses are low-pass filtered. The $60 \%$ drop in membrane time constant we observed between P12 (33 ms) and P15 (14 ms) would dramatically enhance the ability of more mature cells to transmit higherfrequency signals. This is evident in Figure 6, which shows that electrical postsynaptic potentials became narrower and more biphasic between P12 and P15 attributable in part to a decrease in membrane time constant. A shift in the filtering properties of electrical synapses may also contribute to the emergence and spatial propagation of ACPD-induced rhythms.

\section{Increased inhibition strengthens the output of the LTS network}

An increase in the strength of LTS-RS synapses is likely to contribute to the rapid onset of ACPD-induced rhythmic inhibition. Anatomical studies have shown that the total number of GABAergic synapses in the barrel cortex increases approximately threefold between P10 and P15 (Micheva and Beaulieu, 1996; DeFelipe, 1997; White et al., 1997). Our own reconstructions of stained LTS cells revealed growth of dendrites and increased elaboration of axonal arbors, consistent with previous Golgi studies of bitufted interneurons over a similar period (Miller, 1986, 1988).

A more direct test of inhibitory function is provided by our measurements of unitary IPSPs, evoked by LTS spikes and recorded in RS cells; the amplitudes of these increased $50 \%$ between P12 and P15. This is not explained by a developmental shift in membrane potential, which we controlled for, nor is it the consequence of a changing chloride reversal potential, which does occur in some neurons at earlier ages (Owens et al., 1996; Owens and Kriegstein, 2002). We found that the IPSP reversal potential was essentially identical at P12 and P15. The developmental increase in inhibition was, if anything, larger than IPSP amplitude implies, because the input resistance of RS cells decreased significantly. We conclude that the strength of LTS cell-mediated inhibition increased between P12 and P15.

The increase in synaptic strength of the LTS-RS connection probably increased the efficacy of the LTS network as a spikesynchronizing mechanism. Stronger GABAergic contacts should more readily prevent RS cells from spiking during inhibitory events, effectively pushing spikes into closer temporal alignment. However, the probability of the LTS-RS connection remained virtually unchanged during the ages considered in this investigation, and the $52 \%$ change in unitary IPSP amplitude is unlikely to account by itself for the nearly stepwise onset of correlated inhibition between P12 and P15.

Developmental changes of intrinsic properties of LTS cells Although ACPD induced spiking of LTS cells at all tested ages, the spiking frequency increased and the subthreshold patterns changed significantly. Between P12 and P15, both the magnitude and frequency of ACPD-induced LTS rhythms increased. These rhythms influenced the spiking patterns of LTS cells, and the fact that they were strongly anticorrelated with the IPSPs measured in
RS cells (Fig. 3) implies that they are the proximal cause of the mGluR-induced inhibitory patterns.

Changes in input resistance, time constant, and spike frequency adaptation imply changes in the regulation or expression of ion channels between P12 and P15. Perhaps a subpopulation of these channels is modulated by mGluR activation, and this underlies the rhythmogenic properties of activated LTS cells. Subthreshold membrane fluctuations of LTS cells were strongly correlated at P15, even among cell pairs that were not directly coupled electrically. The emergence of correlated LTS rhythms paralleled a more effective spatial use of electrical synapses, which allowed the network to become more functionally synchronous over much larger volumes of cortical tissue.

Together, the emergence of a spike-synchronizing mechanism in neocortex may be strongly influenced by rapid and concurrent changes in several intrinsic properties of LTS cells and their synaptic connections. Rhythmic membrane fluctuations and the spikes they evoke are correlated across neurons via electrical synapses that developed much earlier. The influence of the LTS network on surrounding cortical circuits is further extended by significant growth and strengthening of the inhibitory connections from LTS cells to RS cells.

\section{Significance of the LTS cell synchronizing mechanism}

A glutamate-dependent spike-synchronizing mechanism appears in the neocortex suddenly at the end of the second postnatal week. It is intriguing that this is coincident with the onset of exploratory whisking in rat pups (Welker, 1964). Furthermore, the frequency of whisking (Carvell and Simons, 1990; Berg and Kleinfeld, 2003) matches that of the mGluR-induced LTS rhythms, which suggests that the synchrony they induce plays a role in information processing. In addition, the LTS rhythm may contribute to the generation of certain kinds of electroencephalographic (EEG) rhythms of the forebrain. Normal rats have slow, irregular EEGs at early ages, and these develop into faster, more complex and regular patterns with maturation (Deza and Eidelberg, 1967; Gramsbergen, 1976; Snead and Stephens, 1983). Furthermore, the absence of interneuronal gap junctions is associated with a decrease in gamma oscillations in the connexin36 knock-out mouse (Buhl et al., 2003).

Synchronous activity has been noted in other neural circuits during development. In the retinogeniculate pathway, gap junctions between ganglion cells mediate synchronous retinal waves that help to temporally align the activity of neighboring neurons before the functional maturation of the visual system (Wong et al., 1998; Wong, 1999). Synchronous retinal activity is relayed to the lateral geniculate nucleus (Mooney et al., 1996). Such activity has been implicated in the segregation of inputs in the developing geniculate and in the formation of mature visual circuits (Penn et al., 1998; Torborg et al., 2005). Furthermore, the rapid onset of LTS-mediated synchrony between P12 and P14 parallels the functional emergence of somatosensory maps in layer 2/3 (Stern et al., 2001). Together, our results suggest that the rapid maturation of a synchronizing inhibitory network in neocortex may play an important role in the refinement of a newly functional somatosensory pathway.

\section{References}

Agmon A, Connors BW (1991) Thalamocortical responses of mouse somatosensory (barrel) cortex in vitro. Neuroscience 41:365-379.

Amitai Y, Gibson JR, Beierlein M, Patrick SL, Ho AM, Connors BW, Golomb D (2002) The spatial dimensions of electrically coupled networks of interneurons in the neocortex. J Neurosci 22:4142-4152.

Beierlein M, Gibson JR, Connors BW (2000) A network of electrically coupled interneurons drives synchronized inhibition in neocortex. Nat Neurosci 3:904-910. 
Beierlein M, Gibson JR, Connors BW (2003) Two dynamically distinct inhibitory networks in layer 4 of the neocortex. J Neurophysiol 90:2987-3000.

Berg RW, Kleinfeld D (2003) Rhythmic whisking by rat: retraction as well as protraction of the vibrissae is under active muscular control. J Neurophysiol 89:104-117.

Blatow M, Rozov A, Katona I, Hormuzdi SG, Meyer AH, Whittington MA, Caputi A, Monyer H (2003) A novel network of multipolar bursting interneurons generates theta frequency oscillations in neocortex. Neuron 38:805-817.

Buhl DL, Harris KD, Hormuzdi SG, Monyer H, Buzsaki G (2003) Selective impairment of hippocampal gamma oscillations in connexin-36 knockout mouse in vivo. J Neurosci 23:1013-1018.

Carvell GE, Simons DJ (1990) Biometric analyses of vibrissal tactile discrimination in the rat. J Neurosci 10:2638-2648.

Chu Z, Galarreta M, Hestrin S (2003) Synaptic interactions of late-spiking neocortical neurons in layer 1. J Neurosci 23:96-102.

Cobb SR, Buhl EH, Halasy K, Paulsen O, Somogyi P (1995) Synchronization of neuronal activity in hippocampus by individual GABAergic interneurons. Nature 378:75-78.

Connors BW, Long MA (2004) Electrical synapses in the mammalian brain. Annu Rev Neurosci 27:393-418.

Connors BW, Benardo LS, Prince DA (1983) Coupling between neurons of the developing rat neocortex. J Neurosci 3:773-782.

Deans MR, Gibson JR, Sellitto C, Connors BW, Paul DL (2001) Synchronous activity of inhibitory networks in neocortex requires electrical synapses containing connexin36. Neuron 31:477-485.

DeFelipe J (1997) Types of neurons, synaptic connections and chemical characteristics of cells immunoreactive for calbindin-D28K, parvalbumin and calretinin in the neocortex. J Chem Neuroanat 14:1-19.

Deza L, Eidelberg E (1967) Development of cortical electrical activity in the rat. Exp Neurol 17:425-438.

Engel AK, Fries P, Singer W (2001) Dynamic predictions: oscillations and synchrony in top-down processing. Nat Rev Neurosci 2:704-716.

Fetz EE, Chen D, Murthy VN, Matsumura M (2000) Synaptic interactions mediating synchrony and oscillations in primate sensorimotor cortex. J Physiol (Paris) 94:323-331.

Franceschetti S, Sancini G, Panzica F, Radici C, Avanzini G (1998) Postnatal differentiation of firing properties and morphological characteristics in layer V pyramidal neurons of the sensorimotor cortex. Neuroscience 83:1013-1024.

Fuchs EC, Doheny H, Faulkner H, Caputi A, Traub RD, Bibbig A, Kopell N, Whittington MA, Monyer H (2001) Genetically altered AMPA-type glutamate receptor kinetics in interneurons disrupt long-range synchrony of gamma oscillation. Proc Natl Acad Sci USA 98:3571-3576.

Galarreta M, Hestrin S (1999) A network of fast-spiking cells in the neocortex connected by electrical synapses. Nature 402:72-75.

Galarreta M, Hestrin S (2002) Electrical and chemical synapses among parvalbumin fast-spiking GABAergic interneurons in adult mouse neocortex. Proc Natl Acad Sci USA 99:12438-12443.

Galarreta M, Erdelyi F, Szabo G, Hestrin S (2004) Electrical coupling among irregular-spiking GABAergic interneurons expressing cannabinoid receptors. J Neurosci 24:9770-9778.

Gee CE, Benquet P, Gerber U (2003) Group I metabotropic glutamate receptors activate a calcium-sensitive transient receptor potential-like conductance in rat hippocampus. J Physiol (Lond) 546:655-664.

Gibson JR, Beierlein M, Connors BW (1999) Two networks of electrically coupled inhibitory neurons in neocortex. Nature 402:75-79.

Gibson JR, Beierlein M, Connors BW (2005) Functional properties of electrical synapses between inhibitory interneurons of neocortical layer 4 . J Neurophysiol 93:467-480.

Gramsbergen A (1976) The development of the EEG in the rat. Dev Psychobiol 9:501-515.

Heuss C, Scanziani M, Gahwiler BH, Gerber U (1999) G-proteinindependent signaling mediated by metabotropic glutamate receptors. Nat Neurosci 2:1070-1077.

Katz LC, Shatz CJ (1996) Synaptic activity and the construction of cortical circuits. Science 274:1133-1138.

Kawaguchi Y, Shindou T (1998) Noradrenergic excitation and inhibition of GABAergic cell types in rat frontal cortex. J Neurosci 18:6963-6976.

Levy N, Horn D, Meilijson I, Ruppin E (2001) Distributed synchrony in a cell assembly of spiking neurons. Neural Netw 14:815-824.
Lo Turco JJ, Kriegstein AR (1991) Clusters of coupled neuroblasts in embryonic neocortex. Science 252:563-566.

Long MA, Landisman CE, Connors BW (2004) Small clusters of electrically coupled neurons generate synchronous rhythms in the thalamic reticular nucleus. J Neurosci 24:341-349.

Lopez-Bendito G, Shigemoto R, Fairen A, Lujan R (2002) Differential distribution of group I metabotropic glutamate receptors during rat cortical development. Cereb Cortex 12:625-638.

McCormick DA, Prince DA (1987) Post-natal development of electrophysiological properties of rat cerebral cortical pyramidal neurones. J Physiol (Lond) 393:743-762.

Meyer AH, Katona I, Blatow M, Rozov A, Monyer H (2002) In vivo labeling of parvalbumin-positive interneurons and analysis of electrical coupling in identified neurons. J Neurosci 22:7055-7064.

Micheva KD, Beaulieu C (1996) Quantitative aspects of synaptogenesis in the rat barrel field cortex with special reference to GABA circuitry. J Comp Neurol 373:340-354.

Miller MW (1986) The migration and neurochemical differentiation of gamma-aminobutyric acid (GABA)-immunoreactive neurons in rat visual cortex as demonstrated by a combined immunocytochemicalautoradiographic technique. Brain Res 393:41-46.

Miller MW (1988) Development of projection and local circuit neurons in neocortex. In: Cerebral cortex, pp 133-175. New York: Plenum.

Mooney R, Penn AA, Gallego R, Shatz CJ (1996) Thalamic relay of spontaneous retinal activity prior to vision. Neuron 17:863-874.

Owens DF, Kriegstein AR (2002) Is there more to GABA than synaptic inhibition? Nat Rev Neurosci 3:715-727.

Owens DF, Boyce LH, Davis MB, Kriegstein AR (1996) Excitatory GABA responses in embryonic and neonatal cortical slices demonstrated by gramicidin perforated-patch recordings and calcium imaging. J Neurosci 16:6414-6423.

Peinado A, Yuste R, Katz LC (1993) Extensive dye coupling between rat neocortical neurons during the period of circuit formation. Neuron 10:103-114.

Penn AA, Riquelme PA, Feller MB, Shatz CJ (1998) Competition in retinogeniculate patterning driven by spontaneous activity. Science 279:2108-2112.

Ritz R, Sejnowski TJ (1997) Synchronous oscillatory activity in sensory systems: new vistas on mechanisms. Curr Opin Neurobiol 7:536-546.

Sanes JN (2003) Neocortical mechanisms in motor learning. Curr Opin Neurobiol 13:225-231.

Sholl DA (1953) Dendritic organization in the neurons of the visual and motor cortices of the cat. J Anat 87:387-406.

Snead III OC, Stephens HI (1983) Ontogeny of cortical and subcortical electroencephalographic events in unrestrained neonatal and infant rats. Exp Neurol 82:249-269.

Steinmetz PN, Roy A, Fitzgerald PJ, Hsiao SS, Johnson KO, Niebur E (2000) Attention modulates synchronized neuronal firing in primate somatosensory cortex. Nature 404:187-190.

Stern EA, Maravall M, Svoboda K (2001) Rapid development and plasticity of layer 2/3 maps in rat barrel cortex in vivo. Neuron 31:305-315.

Torborg CL, Hansen KA, Feller MB (2005) High frequency, synchronized bursting drives eye-specific segregation of retinogeniculate projections. Nat Neurosci 8:72-78.

Traub RD, Bibbig A, LeBeau FE, Cunningham MO, Whittington MA (2005) Persistent gamma oscillations in superficial layers of rat auditory neocortex: experiment and model. J Physiol (Lond) 562:3-8.

Welker WI (1964) Analysis of sniffing of the albino rat. Behav 22:223-244.

White EL, Weinfeld L, Lev DL (1997) A survey of morphogenesis during the early postnatal period in PMBSF barrels of mouse SmI cortex with emphasis on barrel D4. Somatosens Mot Res 14:34-55.

Whittington MA, Traub RD (2003) Interneuron diversity series: inhibitory interneurons and network oscillations in vitro. Trends Neurosci 26:676-682.

Wong RO (1999) Retinal waves and visual system development. Annu Rev Neurosci 22:29-47.

Wong WT, Sanes JR, Wong RO (1998) Developmentally regulated spontaneous activity in the embryonic chick retina. J Neurosci 18:8839-8852.

Xiang Z, Huguenard JR, Prince DA (1998) Cholinergic switching within neocortical inhibitory networks. Science 281:985-988.

Young SR, Chuang SC, Wong RK (2004) Modulation of afterpotentials and firing pattern in guinea pig CA3 neurones by group I metabotropic glutamate receptors. J Physiol (Lond) 554:371-385. 